\title{
The Development of the Qatar Healthcare System: A Review of the Literature
}

\author{
Annekathryn Goodman \\ Massachusetts General Hospital, Division of Gynecologic Oncology, Department of Obstetrics and Gynecology, \\ Obstetrics, Gynecology and Reproductive Biology Harvard Medical School, Boston, MA, USA \\ Email: agoodman@mgh.harvard.edu
}

Received 3 March 2015; accepted 18 March 2015; published 25 March 2015

Copyright (C) 2015 by author and Scientific Research Publishing Inc.

This work is licensed under the Creative Commons Attribution International License (CC BY). http://creativecommons.org/licenses/by/4.0/

(c) (i) Open Access

\begin{abstract}
Background: Qatar, one of the smallest and wealthiest countries in the world, is a newly emerging healthcare system. Medical leadership in Qatar has had to create an infrastructure for medical care over the past twenty years. The purpose of this paper is to review the challenges and achievements of the newly emerging Qatar healthcare system. Methods: PubMed was searched using MESH terms: Qatar, healthcare, medical development, medical insurance and medical history. Websites of the World Bank, CIA fact book, Qatar Ministry of Health, Hamad Medical Corporation, Organization for Economic Co-operation and Development and the US State department were searched for information about Qatar's healthcare system and its history. Results: Qatar is a rapidly growing, multicultural country with over 80 nationalities represented. Qatar has developed a healthcare system with universal coverage. Up until 2014, the government has subsidized all care. There are plans to develop a medical insurance system. Conclusions: Qatar has experienced the rapid development of a healthcare system over the past twenty years. The government has centrally controlled growth and development. An examination of the unique challenges to building a Qatari healthcare system will be useful in considering how to develop medical infrastructure in other countries.
\end{abstract}

\section{Keywords}

Qatar Healthcare, Medical Infrastructure, OECD, Hamad Medical Corporation

\section{Introduction}

While the focus in global health has been to improve care for citizens of low and middle income countries where access to care and medical infrastructure are limited, there are lessons to be learned from developing medical systems in countries with greater economic resources such as some of the newer members of the Organization 
for Economic Cooperation and Development (OECD). This paper analyzes the healthcare system of Qatar, one of the smallest and wealthiest countries of the world [1]. Qatar envisions itself becoming the new leader in healthcare, education, and culture in the Arab world and thus it is important to learn more about the country's general history, culture, and demographics. The healthcare system is very new and has undergone significant changes in the brief history of its existence. The purpose of this review is to examine the unique challenges to building a Qatari healthcare system. The lessons learned are useful in considering how to develop medical infrastructure in other countries.

\section{Methods}

PubMed from 1950 to the present was searched using MESH terms in combination: Qatar, healthcare, medical development, medical insurance and medical history. Websites of the World Bank, CIA fact book, Qatar Ministry of Health, Hamad Medical Corporation, Organization for Economic Co-operation and Development and the US State department were searched for information about Qatar's healthcare system and its history. English language papers and websites were evaluated. There was no restriction on types of articles. Data was extracted through review of the articles and websites.

\section{Results and Discussion}

\subsection{History of Qatar}

Qatar occupies a small peninsula that extends into the Persian Gulf. Saudi Arabia is to the west and the United Arab Emirates are to the south. The land is barren and the primary trade was fishing and pearl diving until the middle of the twentieth century [2].

The country was originally ruled by the sheiks of Bahrain. First the Portuguese and then the British imposed trading rules on the regions of the eastern Arabian coast called the Trucial coast. After the breakout of a war between the rulers of Bahrain and the people of the Qatar peninsula in 1867, the British installed the head of a leading Qatari family, Muhamidibn Thani as the region's ruler. Since that time, Qatar has been ruled first as an absolute monarchy and then as a constitutional monarchy by the Al Thani family. The Al Thani ruling family originated from the Al-Maahid tribe of Ushaiqir in the province of Al-Washun of Nejd. They arrived in Qatar in the middle of the $18^{\text {th }}$ century [3].

Tribal and family connections are an extremely important aspect of Qatari culture [4]. This importance is seen today as leading positions of power and prestige are preferentially given to Qataris and to those within the ruling family. The most important positions in Qatar are held by Al Thani family members, or close confidants [5].

Oil was discovered in the 1940s. The country started increasing its wealth in the 1950s and 1960s. Currently, eighty-five percent of Qatar's income comes from oil and natural gas revenues [6].

Qatar, a former British Protectorate, became independent in 1971. Qatar decided against joining the other Trucial states which formed the United Arab Emirates. Both Qatar and Bahrain formed independent and separate nations.

Qatar has become one of the region's wealthiest states due to its enormous oil and natural gas revenues [1]. In 1995, Sheikh Hamad bin Khalifa Al Thani became Emir when he seized power from his father, Khalifa bin Hamad Al Thani, in a peaceful coup d'état. Sheikh Hamad instituted democratic reforms including democratic elections and lifted press censorship. In 1999, women received the right to vote. In June of 2013, the Sheikh's son, Amir Tamin bin Hamad al Thani peacefully took over as the new Emir.

Qatar is now considered a constitutional monarchy. The first constitution was introduced in 2005, which included guarantees for freedom of expression, assembly, and religious expression [5].

Qatar has attracted an estimated $\$ 100$ billion in investment, with approximately $\$ 60$ - 70 billion coming from the US in the energy sector. It is estimated that Qatar will invest over $\$ 120$ billion in the energy sector in the next ten years [1]. Table 1 summarizes Qatar's political history.

\subsection{History of Qatar's Involvement in OECD}

Qatar is one of the wealthiest nations in the world. It has the second highest GDP per capita with 70,000 US dollars due to oil and natural gas [7]. In 2005, Qatar established the Qatar Financial Centre, which attracts financial services and multinational groups. Estimations of growth and development in Qatar are of the order of 140 
Table 1. Political history of Qatar.

\begin{tabular}{|c|c|}
\hline Dates & History \\
\hline 1784-1868 & Bahraini rule \\
\hline 1821 & British protectorate with the British East India Company \\
\hline 1867 & Muhamidibn Thani becomes the region's ruler \\
\hline 1871-1916 & Ottoman rule \\
\hline 1916-1971 & British protectorate \\
\hline 1939 & Discovery of oil \\
\hline 1971 & Independence from Britain with the formation of an independent state \\
\hline 1995 & $\begin{array}{l}\text { Sheikh Hamad bin Khalifa Al Thani seized power from his father, } \\
\text { Khalifa bin Hamad Al Thani, in a peaceful coup d'état }\end{array}$ \\
\hline 1999 & Women's suffrage \\
\hline 2005 & Constitutional monarchy \\
\hline 2013 & $\begin{array}{c}\text { The Sheikh's son, Amir Tamin bin Hamad al Thani peacefully } \\
\text { took over as the new Emir }\end{array}$ \\
\hline
\end{tabular}

billion US dollars.

Qatar joined the OECD Global forum in 2009 and agreed to implement the international standards of transparency and exchange of information [8].

Economic policy in Qatar encourages the development of Qatar's natural gas reserves and increasing private and foreign investment [9]. Despite the worldwide financial crisis, GDP growth continues at 9\% per year. Oil and gas make up 50\% of GDP with 85\% of Qatar's export earnings and 70\% of government revenues.

\subsection{Current Demographics of the Qatar Population}

Only about $20 \%$ of the population is native Qatari. The current population is $2,168,673$, which ranks $146^{\text {th }}$ in world nations' populations [10]. Twenty percent of the Qatar workforce comprises expatriates from other Arab nations. With the majority of the workers coming from India (20\%), Nepal (13\%), Pakistan (7\%), and Sri Lanka (5\%), the Indian subcontinent is a dominant subculture in Qatar. The remainder of the workforce comes from Southeast Asia (Philippines 10\%), and other countries (5\%) [11]. Table 2 summarizes the demographics of Qatar. The net migration rate is 27.35 migrants per 1000, which makes Qatar one of the leading nations for migration ranking at number 2 [10].

The median age in Qatar is 32.6 years. Seventy-seven percent of the population is Muslim although all Qataris are Muslim. Fourteen percent of the population is under age 14 and $85.4 \%$ of the population is between 15 and 65 . Only $1.02 \%$ is over age 65 years.

Statistics for 2014 report the birth rate is 9.95/1000 population, ranking 194 in the world and with a death rate of 1.53 deaths per 1000, ranking at 225, which is the lowest death rate in the world. (The highest death rate is South Africa with 17.49 deaths per 1000). Interestingly, the crude death rate in 2006 was 2.09 per 1000 of the population showing a trend towards better survival in less than a decade. The total fertility rate and the average life expectancy at birth for the same period were 2.67 and 75.8 years respectively [10].

The $80 \%$ migrant community skews these population statistics as these expatriates may go home to their country of origin for births, serious illnesses, and deaths [12].

\subsection{Culture}

Qataris come from three distinct sets of ancestors: the Bedouin, Hadar, and Abd. The Bedoiun come from the nomads of the Arabian Peninsula. Most Hadar come from Iran. The Abd originally came from East Africa as slaves and the term "Alabd" means "slaves". There are subtle socio-cultural differences among them [4]. National identity is closely associated with family. Qataris refer to each other as "brother", "sister", and "cousin" 
Table 2. Demographics of Qatar 2014.

\begin{tabular}{ccc}
\hline World Region & Country of Origin & $\%$ of Population \\
\hline Middle East & Qatar & $20 \%$ \\
& Other Arab Nations & $20 \%$ \\
Central Asia & India & $20 \%$ \\
& Nepal & $13 \%$ \\
& Pakistan & $7 \%$ \\
East Asia & Sri Lanka & $5 \%$ \\
Other & Philippines & $10 \%$ \\
\hline
\end{tabular}

[13]. The Qatari family demographics are changing. While still characterized by a large family size and high fertility rate, there is a change from an extended family to more nuclear families. Women's roles are changing as women become more educated and enter the work force. This demographic change with women is the most prominent challenge that confronts present day Qatari society [14].

In general, foreign workers who make up $80 \%$ of the population have a separate social world from Qataris. However constitutionally, all expatriates are free to wear their national dress and practice their own religion. Migrant workers can be abused and incarcerated during their contract of labor in Qatar [15]. Stress of working conditions can lead to adverse health outcomes [16]. Laws intended to protect workers are reported as rarely enforced [17].

Within the medical system, patients are categorized in the medical record by their country of origin [18]. A traditional blame culture within professional institutions where errors are not tolerated is slowly being addressed through safety drills, data collections, and discussion of cultural differences [19]-[21]. Non-Qatari physicians and nurses are frequently blamed for medical complications or even for long waits in the emergency room and are at risk of deportation [22] [23].

Physical and verbal attacks by Qatari patients and their families against non-Qatari physicians have been reported but the overall incidence is not known. A recent well-publicized attack on an Indian emergency room physician has led to the placement of security guards in hospitals [24]. The malpractice laws of Qatar come out of Sharia law [15]. According to Sharia law, if one causes the injury or death of another, one has to pay blood money or diya to the family. In Qatar, the limit on blood money payments is 200,000 Qatar Riyal (\$55,000 USD) [25].

\subsection{History of the Establishment of a Medical System in Qatar}

In this small and wealthy country, healthcare must be looked at through the lens of the economic power of the country and the vision and guidelines set by the last Emir, HH Sheikh Hamad bin Khalifa Al-Thani, and his wife, HH Sheikha Mozah Bint Nasser Al-Missned.

The first hospital of Qatar, Rumailah Hospital opened in 1957 and is now part of the large public healthcare complex of the country [26]. There are now currently 36 hospitals and numerous clinics in Doha, the capital city [27]. Health centers have also been set-up along the highways for ease of access.

The Emir and his wife have provided billions of dollars of public expenditures to develop both a world premier educational system and a healthcare system [28]. The Qatari vision has been to improve health care through developing state of the art medical facilities and medical education [29].

Qatar Foundation for Education, Science, and Community Development was founded in 1995. Education City is a part of the Qatar Foundation and was developed to provide free world-class education, along with research, and innovation [29]. There are currently six American Universities, one British University, and one French university with branch campuses at Education City.

One of the American Universities, Weill Cornell Medical College in Qatar, was established in 2001 and provides both a premedical curriculum and a four-year medical curriculum [30]. In 2004, an agreement was reached 
between the primary healthcare provider of Qatar, Hamad Medical Corporation, and Weill Cornell to allow medical students to receive clinical education within these hospitals [18].

Current plans are in place for the opening of an ultramodern and all-digital academic medical center called Sidra Medical and Research Center. This new hospital will coordinate with Weill Cornell Medical College and Hamad Medical Corporation to deliver patient care and become a center for medical research [31]

Qatar has also embraced Internet-based education and electronic resources for healthcare. This has been used for teleconferencing technology and also planned electronic medical records [18]. Consumer health websites are increasing in Gulf Cooperation Council countries (GCC: Saudi Arabia, Bahrain, Kuwait, Qatar, United Arab Emirates and Oman) and now number around 925 sites [32]. Research and academic publications in GCC countries has also increased. Qatar, for instance, produced 4265 papers out of the 56,287 academic papers from GCC countries from 1996 through 2013, an impressive 7.6\% of the regions academic output [33].

Nineteen million USD has been dedicated to biotechnology research with the creation of Qatar Science and Technology Park (QSTP). Two and eight tenths percent of total gross domestic product was designated for research in 2010.

Health-care planning, infrastructure, and oversight are under government control.

The first government body was the Ministry of Health [34]. Governmental reorganization is common. The National Health Authority (NHA) was established in 2005 to replace the Ministry of Public Health. The NHA oversaw the necessary medical services and delegated different services to various public health institutions.

The Supreme Council of Health (SCH) was then established by the previous Emir in 2009 and currently oversees healthcare in Qatar. This governmental agency regulates the medical market place. The SCH promotes evidence-based medicine and many public health initiatives.

The division of healthcare departments within SCH is outlined in Table 3. Health-care organizations include the nonprofit public sector services and the private sector faculties.

In 1979, Hamad Medical Corporation (HMC) was established by decree from the Emir of Qatar [27]. HMC is a nonprofit health care provider than manages the bulk of healthcare in Qatar. There are eight hospitals (Rumallah, Hamad General, Women's Hospital, National Center for Cancer care and research, Heart Hospital, Al Wakra, Al Khor, and Fahad bin Jassim Kidney center) that are managed by HMC.

Since 1979, HMC has been responsible for building this network of hospitals, which include both a primary care emphasis and tertiary hospitals in the capital city of Doha.

In 2007, the Joint Commission International, the US-based organization that oversees the accreditation of hospitals outside of the United States, awarded accreditation for the HMC facilities. HMC is also the first hospital system in the Middle East to achieve institutional accreditation from the Accreditation Council of Graduate Medical Education-International (ACGME-I). ACGME unifies criteria for compliance in teaching and educational goals for how medical graduates are trained through residency, internship and fellowship programs.

Besides HMC, the Qatari government has also encouraged the private sector to play a greater role in providing healthcare to the public. The country's first private hospital opened in late 1999, and private practices and

Table 3. Supreme council of health: structure and function.

\begin{tabular}{|c|c|c|}
\hline Department & Subdivisions & Comments \\
\hline 1) E-health department & & Planned opening by 2015 \\
\hline 2) Department of Research & & Established 2008 \\
\hline 3) Department of Public Health & & $\begin{array}{l}\text { A continuation of the previous health } \\
\text { ministry }\end{array}$ \\
\hline $\begin{array}{l}\text { a) Emergency preparedness and disease } \\
\text { control }\end{array}$ & $\begin{array}{l}\text { 1) Emergency preparedness } \\
\text { 2) Disease control } \\
\text { a) Food borne disease program } \\
\text { b) STI and AIDS program } \\
\text { c) TB program } \\
\text { d) Malaria and Parasitic and vector } \\
\text { disease control }\end{array}$ & \\
\hline \multicolumn{3}{|l|}{ b) Immunization and vaccine control } \\
\hline c) Surveillance and outbreaks section & & \\
\hline
\end{tabular}


clinics (both medical and dental) are now available.

Laws governing private practice are strict, and licensing by the Supreme Council of Health is mandatory for all establishments and each of their medical and nursing staff.

By one report, private medical service facilities have expanded to represent $67 \%$ of all the country's health services providers.

The World Health Organization (WHO) recently ranked Qatar at the top of the per capita health expenditure list among the Gulf Cooperative Council (GCC). In 2010, spending on healthcare accounted for $2.0 \%$ of the country's GDP [35]. Given the extreme wealth of the country, the percentage of GDP does not give the full picture of expenditures.

Qatar's per capita health expenditure is USD 1561 (measured at actual population), and USD 2756 (measured at adjusted population), which is comparable to the OECD average of USD 2984 [35].

Seventy-seven percent of current healthcare expenditures are in the public sector. However, the proportion of healthcare spending by the private sector has been steadily rising since 2003 from $17 \%$ to $22.55 \%$ in 2010 [10]. This probably reflects the government's recent encouragement of private sector healthcare.

The Supreme Council of Health (SCH) published their first comprehensive analysis of expenditures for years 2009 and 2010. Their website outlines expenditures by different health sectors [35]. (One Us dollar equals 3.63 Qatari Rial).

The healthcare system is available to all both Qataris and expatriates. Qatar has a public health service that provides free or highly subsidized healthcare.

All Qataris receive free treatments. Expatriates can pay a small fee out of pocket or purchase a health card. A Health card can be purchased for 25 US dollars and will cover a person for one year.

Medicine is heavily subsidized. For instance, a course of antibiotics for a government pharmacy costs 1.5 US dollar. The one possible exception to free or heavily subsidized care may be treatment for highly specialized services [36].

The Supreme Council is focusing on health reform by the development of medical insurance, electronic record keeping and data collection, and improvements in quality assurance and evidence based medicine at its various hospitals [37]. Qatar is currently developing a system of mandatory universal health insurance. The Social Health insurance plan will require government sponsored health insurance for all Qatari citizens. Sponsoring companies will be required to provide insurance for working expatriates [38].

The Qatar national Health Strategy website describes the goals of insurance and the planned development of infrastructure [39]. The vision is for a combination of government and corporate clients to share in healthcare insurance. The government hopes to develop a system that allows good data collection.

The prerequisite infrastructure will be the conversion of the existing paper records to electronic record keeping. All diagnoses will be coded using the Australian coding system.

In 2006 there were 27.6 physicians and 73.8 nurses per 10,000 of the population [14]. According to the SHC 2011 report, in 2010, there were a total of 4482 doctors and 7410 nurses, and 2067 hospital beds. The majority (90\%) of the physicians and nurses are non-Qatari [35]. The Qatar health system has improved in the last decade, but there is still the need for more medical workers in primary health care [40].

\subsection{Current Challenges of the Healthcare System in Qatar}

There has been improvement in health and a decline in overall mortality over the decades since Qatar's independence. Data from several observational studies have confirmed the relationship between illness and death and socioeconomic status. For instance, a retrospective study looked at maternal and neonatal survival in the Qatar over a period of 35 years (1974-2008). During these 35 years, there was a remarkable decline $(\mathrm{P}<0.001)$ in Qatar's neonatal mortality rate from 26.27/1000 in 1974 to 4.4/1000 in 2008. Qatar's maternal mortality rate was 11.6/100,000 in 2008. The reduction in poverty, increase in maternal education, and improved prenatal health care were temporally associated with a significant improvement in survival [41].

Of note, there may be some disparities in healthcare between the Qatari nationals and the larger expatriate community. For instance, neonatal mortality was evaluated in the years 2008 to 2011 at Women's Hospital [42]. Neonatal mortality rates, overall in Qatar, declined very little between 2008 and the first quarter of 2011. A total of 4909 live births and 21 neonatal deaths were recorded. The neonatal mortality rate was 4.28/1000 live births (corrected neonatal mortality rate 2.85/1000). Fifteen of the 21 neonatal deaths were in non-Qatari babies. 
However, prospective disparity research needs to be initiated to fully evaluate disparities in healthcare among the different populations of Qatar. Gender disparities have been looked at in diabetic management. In an observational cohort study on the impact of primary care at health centers on diabetic control, outcomes significantly improved for males but not females [43].

There has been an intensive focus on quality assurance and evaluation of the existing health programs in Qa$\operatorname{tar}$ [35]. The current challenges include a lack of Qatari healthcare providers. Most of the professional expertise in medicine has been imported. However, the long-term investment in the medical system by non-Qatari doctors and nurses may be limited as many of the hired expatriate physicians will not stay in Qatar long term. Secondly, there is a high intolerance of adverse outcomes and medical complications [19]-[21]. This can discourage doctors and nurse from performing complex procedures and intervening on complex, significantly ill patients where the risk of poor outcomes is increased [44] [45].

\section{Conclusions: Lessons for the Development of Other Healthcare Systems}

The success of a healthcare program can be measured in a variety of complex and interrelated ways. One analytic approach uses a variety of domains to look at the whole picture [46]. Design, implementation, and functionality of the model of healthcare can be evaluated in this manner. The domains include accessibility, quality, costeffectiveness, health impact, transferability, and sustainability.

Unlike most high-income countries whose health care systems have evolved over decades and in some cases, centuries, Qatar has experienced exponential growth and development over less than 50 years [47]. They have imported healthcare systems from other countries and currently struggle to mold these foreign systems to their unique indigenous culture and a multicultural infusion from over 80 other countries. There has been an extraordinary development of both medical infrastructure and academic inquiry over the past two decades.

The Qatari government has controlled and regulated all aspects of healthcare growth. Currently, Qatar is converting their universal government funded medical care to a model similar to the bureaucratic American form of healthcare insurance [38] [39].

Qatar has started keeping detailed statistics on the demographics of their patients and their diagnoses [34]. With time, outcome measures will be evaluated. In many ways, this small, wealthy country is like a greenhouse garden - well tended and intensely observed. Health policy analysts can learn from Qatar by observing the health costs, outcomes, failures, and successes that will be reported out of Qatar over the next decade.

\section{References}

[1] World Bank (2014) GINI Index. http://data.worldbank.org/indicator/SI.POV.GINI/

[2] Qatar (2015) Welcome to Qatar: History. Embassy of the state of Qatar in Washington DC. http://www.qatarembassy.net/page/history

[3] CIA (2015). https://www.cia.gov/library/publications/the-world-factbook/geos/qa.html

[4] Al Dulaimi, S.H. and Bin Sailan, M.S. (2011) Examining the National Culture of Qatar. Australian Journal of Basic and Applied Sciences, 5, 727-735.

[5] US State Department (2014) “US State Department Qatar Page”. http://www.state.gov/r/pa/ei/bgn/5437.htm

[6] Sorkhabi, R. (2012) The Qatar Oil Discoveries.GEO Expro. http://www.geoexpro.com/article/The_Qatar_Oil_Discoveries/d5544f3c.aspx

[7] UNDP United Nations Global Development Network (2014) Human Development Index and Its Components. http://hdr.undp.org/sites/default/files/hdr14-report-en-1.pdf

[8] OECD, Organisation for Economic Co-Operation and Development (2009) Peer Review Report of Qatar-Phase 1: Legal and Regulatory Framework.

http://www.oecd.org/countries/qatar/peerreviewreportofqatar-phase1legalandregulatoryframework.htm

[9] Zughaibi, K. and Kabbani, B. (2014) State of Qatar: Economic Overview. http://www.gulfbase.com/GCC/Index/6

[10] SESRIC (2013) Statistics and Databases: Qatar. http://www.sesrtcic.org/oic-member-countries-infigures.php?c_code=43\&cat_code $=7$

[11] Qatar Census (2010) Qatar Our Census Our Future. http://www.qsa.gov.qa/QatarCensus/Default.aspx

[12] Soman, R. (2013) Expatriates Constitute 94\% of the Labour Market in Qatar. In Economy, Employment, Socioeconomics, TOP 20. http://www.bqdoha.com/2013/09/expatriates-constitute-94-of-the-labour-market-in-qatar 
[13] Countries and Their Cultures: Qatar. (2015) http://www.everyculture.com/No-Sa/Qatar.html

[14] Al-Ghanim, K.A. (2009) Violence against Women in Qatari Society. Journal of Middle East Women's Studies, 5, 8093. http://dx.doi.org/10.2979/MEW.2009.5.1.80

[15] US Department of State (2014) 2013 Human Rights Report: Qatar. http://www.state.gov/j/drl/rls/hrrpt/humanrightsreport/index.htm\#wrapper

[16] Kronfol, Z., Saleh, M. and Al-Ghafry, M. (2014) Mental Health Issues among Migrant Workers in Gulf Cooperation Council Countries: Literature Review and Case Illustrations. Asian Journal of Psychiatry, 10, 109-113. http://dx.doi.org/10.1016/j.ajp.2014.03.003

[17] Conn, D. (2013) Qatar 2022 World Cup Will Exploit Migrant Workers, Says Report. Human Rights Watch Chronicles Abuse of Workers in Gulf State. Forced Labour, Low Pay and Insanitary Conditions Rife. The Guardian. http://www.guardian.co.uk/football/2013/jan/29/qatar-2022-world-cup-exploit-workers

[18] Elnashar, M., Abdelrahim, H. and Fetters, M.D. (2012) Cultural Competence Springs Up in the Desert: The Story of the Center for Cultural Competence in Health Care at Weill Cornell Medical College in Qatar. Academic Medicine, 87, 759-766. http://dx.doi.org/10.1097/ACM.0b013e318253d6c6

[19] Sankaranarayanan, K. (2008) A Paradigm Shift from Blame to Fair and Just Culture: A Middle East Hospital Experience. http://www.innovationarabia.ae/system/files/documents/HBMSU_health_Conference_2014.pdf\#page=92

[20] Kilshaw, S., Sole, K., Al Tamimi, H. and El Taher, F. (2013) Culture Embodied: An Anthropological Investigation of Pregnancy (and Loss) in Qatar. ARC'13 Qatar Foundation Annual Research Conference. http://www.qscience.com/doi/pdfplus/10.5339/qfarf.2013.SSHO-06

[21] Al-Ishaq, M.A.L. (2009) Nursing Perceptions of Patient Safety at Hamad Medical Corporation in the State of Qatar. Indiana University-Purdue University Indianapolis (IUPUI) ScholarWorks. https://scholarworks.iupui.edu/handle/1805/1848

[22] Diajiworld.com. (2007) Expats Seen as Threat “Could Be Deported”. 10 November 2007. http://www.daijiworld.com/news/news_disp.asp?n_id=40073\&n_tit=Qatar\%3A+Expats+Seen+as+Threat+\%91Could+ be+Deported\%92+

[23] Al Thani, T.B.H. (2009) Law No. 4 of 2009 Regulating the Entry and Exit of Expatriates in Qatar and Their Residence and Sponsorship. http://www.brasembdoha.com.qa/files/Law_No\%204-2009_\%20Lawyer_translation.pdf

[24] Khatri, S.S. (2012) Attack on HMC Doctor Raises Tough Questions about Race Relations, Hospital Care in Qatar. Doha News 2012. http://dohanews.co/attack-on-hmc-doctor-raises-tough-questions-about-race/

[25] Al Jandaly, B. (2009) Blood Money in Islamic Law. Gulf News.com. http://gulfnews.com/uaessentials/residents-guide/legal/blood-money-in-islamic-law-1.442003

[26] Facts, U. (1957) Medicine by the Persian Gulf. The British Medical Journal, 1, 514. http://dx.doi.org/10.1136/bmj.1.5017.514

[27] Hamad (2013) Hamad Medical Corporation Website. http://www.hmc.org.qa/en/index.aspx

[28] Lewis, S. (2011) Academic Health System. Qatar's Quest for Excellence. Health Service Journal, 121, $26-27$.

[29] Chouchane, L., Mamtani, R., Al-Thani, M.H., Al-Thani, A.A., Ameduri, M. and Sheikh, J.I. (2011) Medical Education and Research Environment in Qatar: A New Epoch for Translational Research in the Middle East. Journal of Translational Medicine, 9, 16. http://dx.doi.org/10.1186/1479-5876-9-16

[30] Hillhouse, E., Al Kuwari, H. and Sheikh, J. (2012) Establishment of a Model Academic Health System in Qatar. Lancet, 379, 694-695. http://dx.doi.org/10.1016/S0140-6736(11)61026-X

[31] Sidra Medical and Research Center. (2015) http://www.sidra.org/introduction/

[32] Weber, A.S., Verjee, M., Rahman, Z.H., Ameerudeen, F. and Al-Baz, N. (2015) Typology and Credibility of Internet Health Websites Originating from Gulf Cooperation Council Countries. Eastern Mediterranean Health Journal, 20, 804-811.

[33] Meo, S., Hassan, A., Aqil, M. and Usmani, A. (2015) Medical Education Research in GCC Countries. BMC Medical Education, 15, 8. http://dx.doi.org/10.1186/s12909-015-0293-6

[34] Gerard, B. (1973) Qatar into the Seventies. Qatar: A Forward-Looking Country with Centuries Old Traditions. Editions Delroisses for the Ministry of Information, Qatar, Boulogne.

[35] Al Qahntani, A.K. (2011) Qatar's National Health Accounts-1st Report Years 2009, 2010: A Baseline Analysis of Health Expenditure and Utilization. Supreme Council of Health Policy Affairs Directorate. www.who.int/nha/country/.../qatar-2009-2010-nha_report.pdf

[36] Al-Hajri, M., Bener, A., Balbaid, O. and Eljack, E. (2011) Knowledge and Practice of Travel Medicine among Primary Health Care Physicians in Qatar. Southeast Asian Journal Tropical Medicine and Public Health, 42, 1546-1552. 
[37] Al-Kubaisi, N.J., Al-Dahnaim, L.A. and Salama, R.E. (2010) Knowledge, Attitudes and Practices of Primary Health Care Physicians towards Evidence-Based Medicine in Doha, Qatar. Eastern Mediterranean Health Journal, 16, 11891197.

[38] Pallot, P. (2014) Qatar Makes Medical Insurance Compulsory for Expats. http://www.telegraph.co.uk/finance/personalfinance/expat-money/11154852/Qatar-makes-medical-insurance-compulso ry-for-expats.html

[39] National Health Strategy (2015) Social Health Insurance Establishment. http://www.nhsq.info/strategy-goals-and-projects/affordable-services/health-insurance-establishment

[40] Bener, A. and Al Mazroei, A. (2010) Health Services Management in Qatar. Croatian Medical Journal, 51, 85-88. http://dx.doi.org/10.3325/cmj.2010.51.85

[41] Rahman, S., Salameh, K., Bener, A. and El Ansari, W. (2010) Socioeconomic Associations of Improved Maternal, Neonatal, and Perinatal Survival in Qatar. International Journal of Women's Health, 2, 311-318. http://dx.doi.org/10.2147/IJWH.S12426

[42] Rahman, S., El Ansari, W., Nimeri, N., El Tinay, S., Salameh, K., Abbas, T., et al. (2012) Have Neonatal Mortality Rates in the State of Qatar Become Static? A PEARL Study Analysis. Eastern Mediterranean Health Journal, 18, 12011208.

[43] Bener, A., Abdulmalik, M., Al-Kazaz, M., Sanya, R., Buhmaid, S., Al-Harthy, M., et al. (2012) Does Good Clinical Practice at the Primary Care Improve the Outcome Care for Diabetic Patients? Gender Differences. Primary Care Diabetes, 6, 285-292. http://dx.doi.org/10.1016/j.pcd.2012.04.007

[44] DeLong, T.J. and DeLong, S. (2011) The Paradox of Excellence. Harvard Business Review, 89, 119-123, 139.

[45] Farson, R. and Keyes, R. (2002) The Failure-Tolerant Leader. Harvard Business Review, 80, 64-71, 148.

[46] Hollander, M.J., Miller, J.A. and Kadlec, H. (2010) Evaluation of Healthcare Services: Asking the Right Questions to Develop New Policy and Program-Relevant Knowledge for Decision-Making. Healthcare Quarterly, 13, 40-47. http://www.longwoods.com/content/21997 http://dx.doi.org/10.12927/hcq.2013.21997

[47] Prendville, G.R.G. (2007) Chairman’s Reflections. Heart Views, 7, 157-164. http://site.hmc.org.qa/heartviews/vol7No4/PDF/SPECIAL_SECTION.pdf 